\title{
Estimation of the Daily Global Solar Radiation using RadEst 3.00 software-A Case Study at Low land Plain Region of Nepal
}

\author{
Khem N. Poudyal ${ }^{{ }^{*}}$, Binod K. Bhattarai ${ }^{1}$, Balkrishna Sapkota ${ }^{1}$, Berit Kjeldstad ${ }^{2}$ \\ ${ }^{1}$ Institute of Engineering, Tribhuvan University, Kathmandu, Nepal, \\ ${ }^{2}$ Department of Physics, Norweagian University of Science and Technology, Norway \\ E-mail: khem.poudyal@yahoo.com
}

\begin{abstract}
The RadEst 3.00 verson software estimates daily global solar radiation at low altitude plain area using meteorological parameters precipitation, maximum and minimum temperatures and solar radiation of Simara $\left(\right.$ Lat. $27.15^{\circ} \mathrm{N}$, Lon. $84.98^{\circ} \mathrm{E}$, and Alt.137m). Radiation is calculated as the product of the atmospheric transmissivity of radiation times radiation outside the earth atmosphere. The model parameters are fitted in two years data by iterative procedures. An accurate knowledge of solar radiation distribution in each particular geographysical location is crucial for the promotion of solar energy technology. The values estimated by the models are compared with measured radiation data. The performance of the model was evaluated using the statistical tools such as root mean square error (RMSE), mean bias error (MBE), Coefficient of Residual Mass (CRM) and coefficient of determination $\left(r^{2}\right)$. The empirical solar radiation models that showed better results using $B C, C D$, and $D B$ and among them Modular DCBB is the best model for this location The finding coefficients of different models can be utilized for the estimation of solar radiation at the similar meteorological sites of Nepal.
\end{abstract}

Keywords: global solar radiation, RadEst 3.00 software, precipitation, air temperature, transmissivity

\section{Introduction}

Nepal is situated in between $26^{\circ} 22^{\prime}-30^{\circ} 27^{\prime} \mathrm{N}$ latitude and $80^{\circ} 4^{\prime}-88^{0} 12^{\prime} \mathrm{E}$ longitude so it is closer to the solar belt. The annual average global solar radiation is $3.6-6.2 \mathrm{kWh} / \mathrm{m}^{2} /$ day and the sun shines for about 300 days in a year ${ }^{1,2}$. The global solar radiation increases in altitude mainly due to decreasing amounts of air molecules, ozone, aerosols and clouds in the atmosphere as well as due to snow covered surfaces. Thus there is not only the single source dependence factor ${ }^{3}$.

The global solar radiation is an important weather variable for several agro-environmental studies.The number of ground level weather stations recording daily global solar radiation is very small compared to the number recording air temperature and precipitation ${ }^{4}$. The need for solar radiation estimates at sites where it is not measured has grown in the past years, as the spatial scope of research into land-surface processes has expanded from local, regional continental and global scale ${ }^{5}$. The incoming solar radiation has significant role for the optimal design of solar energy system, hydrological and crop growth modeling. For the instance, it is key input for estimating potential evapotranspiration which play a major role in the design of water supply storage reservoirs and irrigation systems. Inspite of the importance of global solar radiation data, its measurements is not frequently available especially in the developing countries like Nepal ${ }^{6}$.

The total solar radiation can be easily estimated from sunshine duration measurements using several equations with varying degree of complexity following the classic work of A. Angstrom ${ }^{7}$. Actually, models that estimate solar radiation from sunshine hour fared better than models involving at temperature

* Corresponding author 
and precipitation by ${ }^{8,9,10}$. However it is known that sunshine hour is not measured even in the most of standard meteorological stations as ambient temperature and precipitation. Thus, the solar radiation estimation models based on daily ambient temperature difference and precipitation are attractive and viable options. These models are really simple, but allow widespread application because precipitation and ambient temperature are observed practically in all of the meteorological stations in the world.

This paper describes RadEst 3.00 software that allows the user to estimate the daily global solar radiation data from maximum and minimum air temperatures and precipitation and geographysical location. The best model can be used to relate global solar radiation, temperature and precipitation for the further study in similar geographysical regions as well as for the development of solar energy technology in Nepal.

Bristow and Campbell ${ }^{11}$ demonstrated that a relationship exists between radiation transmissivity through the atmosphere and the diurnal range in near-surface air temperature. This model has been used in numerous studies, and improvements have been developed over the last years. In the models ${ }^{12,13}$, the correction factor accounting for seasonality effects occurring in mid-latitude area was introduced. This model was implemented in the weather generators ${ }^{14,15}$. In addition, more recently a further improvement was proposed Donatelli and Bellocchi ${ }^{16}$, better accounting for seasonality at a wide variety of locations M. Donatelli $1^{17}$.

\section{Methodology}

The RadEst 3.00 software websites $^{18,19}$ is a MS Windows (98/NT/2000/XP program which allows evaluating the daily estimation of global solar radiation values for a given latitude. These four models (Bristow-Campbell, Campbell- Donatelli, Donatelli- Bellocchi and Modular Donatelli- Campbell Bristow -Bellocchi (MDCBB) evaluate the results by graphical and statistical tools.

The models adopt the following parameters;

$t t_{i}$, transmissivity,

- $\tau$, clear sky transmissivity,

- $\Delta T$, average monthly temperature $\left({ }^{0} \mathrm{C}\right)$,

- $T_{\max }$, daily maximum air temperature $\left({ }^{0} \mathrm{C}\right)$,

- $\quad T_{\text {min }}$, daily minimum air temperature $\left({ }^{0} \mathrm{C}\right)$,

- $\quad b$, empirical parameter which is the temperature range coefficient or multiplier for $\Delta T$. It is worth to underline that greater the value of $b$ greater will be the estimated solar radiation. The parameter $b$ is the key parameter for all models,

- $\quad c$, empirical parameter which is very sensitive, i.e. a small change in $c$ causes large change in estimated solar radiation,

- $T_{n c}$, empirical parameter which is the summer night temperature factor,

- $\quad c_{1}$, parameter for seasonal variation magnitude,

- $c_{2}$, parameter for seasonal variation profile,

- $\quad i$ and $D O Y$ both represent day of the year, $\mathrm{i}=1$ to 365 ,

- $f\left(T_{\text {avg }}\right)$, function of average temperature,

- $f\left(T_{\min }\right)$, function of minimum temperature.

\section{Models}

All the models estimated the atmospheric transmissivity of global solar radiation based on the difference between maximum and minimum air temperature. The estimated value of radiation is calculated 
as the product of the estimated transmissivity times the value of potential radiation outside the earth atmosphere as,

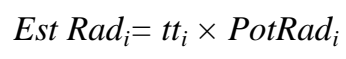

where, $E s_{t} \operatorname{Rad}_{i}$ - estimated radiation $\left(\mathrm{MJ} \mathrm{m}^{-2}\right.$ day $\left.^{-1}\right)$

PotRad $_{i}$ - Potential radiation outside the atmosphere $\left(\mathrm{MJ} \mathrm{m}^{-2}\right.$ day $\left.^{-1}\right)$,

Potential Radiation $\left(\right.$ PotRad $\left._{d o y}\right)=117.5 \times d d 2 \times\{h s \times \operatorname{Sin}($ lat $) \times \operatorname{Sin}(d e c)+\operatorname{Cos}($ lat $) \times \operatorname{Cos}(d e c) \times \operatorname{Sin}$ $(h s)\} / \pi$

Where, PotRad $_{\text {doy }}=$ Potential Radiation, doy - day of the year

$d d 2=$ factor accounting for distance of the sun $=1+0.0334 \times \operatorname{Cos}(0.01721 \times$ doy -0.0552$)$

hs $=$ half day length $=\operatorname{Cos}^{-1}\{$-Tan (dec) $\times$ Tan (lat) $\}$

dec $=$ solar declination $=\operatorname{Sin}^{-1}[0.39785 \times \operatorname{Sin}\{4.869+0.0172 \times$ doy+0.03345 $\times \operatorname{Sin}(6.224+0.0172 \times$ doy)\}]

\section{There are four models in RadEst 3.00 software which are briefly described as below}

\section{Bristow and Campbell Model (1984)}

Bristow and Campbell (BC) is the first model is used to derive and develop the other models. This $\mathrm{BC}$ model exploits the relationship between diurnal air temperature range and radiation load to estimate the daily flux of incoming solar radiation. This model has been used in numerous studies and improvements have been made over the last years ${ }^{4}$.

$$
\begin{gathered}
t_{i}=\tau\left[1-\exp \left(\frac{-b \Delta T_{i}^{C}}{\operatorname{month} \Delta T}\right)\right] \\
\Delta T=\operatorname{Tmax}_{i-}\left(\operatorname{Tmin}_{i}+\operatorname{Tmin}_{i+1}\right) / 2,
\end{gathered}
$$

\section{Campbell and Donatelli Model (1998)}

Campbell and Donatelli model is the second model to estimate the solar radiation which is derived from the modification of the first BC model. In CD model, a correction factor accounting for seasonality effects occurring in mid-latitude areas was introduced.

$$
\begin{gathered}
t t_{i}=\tau\left[1-\exp \left\{-b \times f(\text { Tavg }) \times \Delta T_{i}^{2} \times f(\text { Tmin })\right\}\right] \\
\Delta T=\operatorname{Tmax}_{i}-\left(\operatorname{Tmin}_{i}+\operatorname{Tmin}_{i+1}\right) / 2, \\
f(\text { Tavg })=0.017 \exp f \exp \left(-0.053_{-} \text {Tavg }\right) \\
\text { Tavg }=(\text { Tmaxi }+ \text { Tmini }) / 2 \\
f(\text { Tmin })=\exp (\text { Tmini }) / \text { Tnc })
\end{gathered}
$$




\section{Donatelli and Bellocchi Model (2001)}

The Donatelli and Bellochi Model is the third model to estimate the solar radiation from air temperature data. In addition, the assumptions made by the previous models, it is mainly differ from the previous ones by better accounting explicitly for the effect of the seasonal variation of the clear sky transmissivity and the DeltaT using a trigonometric function via parameters $\mathrm{c} 1$ and $\mathrm{c} 2$ which are the general seasonality factors in (Donatelli Bellochhi model.

$$
t t_{i}=\tau[1+f(i)]\left[1-\exp \left\{\frac{-b \Delta T_{i}^{2}}{\Delta T_{\text {week }}}\right\}\right]
$$

where,

$$
\Delta \mathrm{T}=\operatorname{Tmax}_{\mathrm{i}}-\left(\operatorname{Tmin}_{\mathrm{i}}+\operatorname{Tmin}_{\mathrm{i}+1}\right) / 2,
$$

Tmax is daily air maximum temperature ${ }^{0} \mathrm{C}$, Tmin is daily air minimum temperature ${ }^{0} \mathrm{C}$

$$
\begin{gathered}
\mathrm{f}(\mathrm{i})=\mathrm{c}_{1}\left\{\sin \left(\mathrm{i} \times \mathrm{c}_{2} \times \pi / 180\right)+\cos \left(\mathrm{i} \times \mathrm{f}\left(\mathrm{c}_{2}\right) \times \pi / 180\right)\right\} \\
\mathrm{f}\left(\mathrm{c}_{2}\right)=1-1.90 \mathrm{c}_{3}+3.83 \mathrm{c}_{3}^{2} \\
\mathrm{c} 3=\mathrm{c} 2-\text { integer }(\mathrm{c} 2),
\end{gathered}
$$

\section{Modular DCBB Model}

The fourth model DCBB is based on air temperature data to estimate the global radiation. It includes features of the previous three models allowing switching such features more specially, the trigonometric function which allows accounting for a seasonal variation of both the clear sky transmissivity and the DeltaT can be excluded by setting the parameter $\mathrm{c} 1=0$.

$$
t t_{i}=\tau[1+f(i)]\left[1-\exp \left\{\frac{-b \Delta T^{2} f\left(T_{\min }\right)}{\Delta T_{a v g}}\right\}\right],
$$

where,

$$
\begin{gathered}
\Delta T=\operatorname{Tmax}_{i}-\left(\operatorname{Tmin}_{i}+\operatorname{Tmin}_{i+1}\right) / 2 \\
f(i)=c_{1}\left\{\sin \left(i \times c_{2} \times \pi / 180\right)+\cos \left(i \times f\left(c_{2}\right) \times \pi / 180\right)\right\} \\
f\left(c_{2}\right)=1-1.90 c_{3}+3.83 c_{3}^{2} \\
C_{3}=c_{2}-\operatorname{integer}\left(c_{2}\right),
\end{gathered}
$$

Files Format

The Environdata Weather Master 2000 instrument is installed at Simara (Lat.27.15 N, Lon. $84.98^{\circ} \mathrm{E}$, and Alt.137m). It is compact, robust, automatic weather station. It consists of six electronic weather sensors, Easi Access Windows database and reporting sophisticated software, automatic evaporation calculation, internal data logger and battery, solar panel and powder-coated stand. Each sensor continuously sends information to the data logger, which processes and stores the data in its memory. The operating temperature is from $-15.0^{\circ} \mathrm{C}$ to $+60.0^{\circ} \mathrm{C}$ and resolution is $0.1{ }^{\circ} \mathrm{C}$. Global incoming radiation with cosine correction accuracy and cosine corrected are $+/-5 \%$ and $+/-3 \%$ c respectively ${ }^{20}$. 
All these models take into account of daily precipitation, maximum and minimum temperature and total solar radiation i.e. (DOY, Rain, Tmax, Tmin, Rad) data of each year without headers in ASCII format. It means that all models should arrange the data day of one year (from 1 to 365 ), rainfall ( $\mathrm{mm}$ ), maximum temperature Tmax $\left({ }^{0} \mathrm{C}\right)$, minimum temperature Tmin $\left({ }^{0} \mathrm{C}\right)$ and global solar radiation in Rad $\left(\mathrm{MJ} / \mathrm{m}^{2} /\right.$ day). The daily values of global solar radiation have been estimated for two years (2006 and 2008) of input data of Simara.

\section{Input Format}

In the RadEst 3.00 model, it is necessary to input the latitude, longitude and altitude of the measured locations for four models. In spite of this, select the clear sky transmissivity ranges from 0.60-0.80. The latitude is explicitly used in the expression of potential radiation and clear sky transmissivity is used in the expression of transmissivity coefficient of atmospheric radiation in each model. It is also used in the calculation of global solar radiation and its plot.

Analysis

First of all the data is carried out using auto optimization (AO) and parameter fitting (PF) whereas at least 2 years data is required for the comparison as well as estimation of global solar radiation. AO can be less accurate method as compared to PF. Thus AO has no significant effect so it is not considered in this analysis. PF is more convenient because of key parameters which are directly related to the affecting factors of solar radiation. It is used by varying the different parameters to get closer value in between estimated and measured radiation. After the analysis the different models give the value of root mean square error (RMSE), coefficient of residual mass (CRM), mean bias error (MBE) and coefficient of determination $\left(r^{2}\right)$. Those tools help to justify the model estimated value and measured value of radiation.

\section{Results and Discussion}

All four models were calibrated using parameter fitting (PF) on the basis of 2006 data of Simara by minimizing Coefficient of Residual Mass (CRM), MBE and RMSE should be smaller as for as possible or nearly equal zero. The value of $r^{2}$ should be greater as far as possible. Finally the equal values of measured and model estimated radiation are found in PF in 2006. The finding value of model estimated and measured value $15.7 \mathrm{MJ} / \mathrm{m}^{2}$ is found. Measured and Model estimated Average Value, Maximum Value and Yearly total Value of Global solar Radiation of Simara 2006 is given in Table 1. The Table 1 data shows that there is nearly closer values is found in DCBB model to compare in $\mathrm{BC}, \mathrm{CD}$ and $\mathrm{DB}$ hence DCBB is the best model in 2006 for the estimation of global solar radiation.

Table 1: Measured and Model estimated Average Value, Maximum Value and Yearly total Value of Global solar Radiation of Simara 2006

\begin{tabular}{|c|c|c|c|c|c|c|}
\hline \multirow{2}{*}{ Models } & \multicolumn{2}{|c|}{ Average value $\left(\mathrm{MJ} / \mathrm{m}^{2}\right)$} & \multicolumn{2}{c|}{ Maximum Value $\left(\mathrm{MJ} / \mathrm{m}^{2}\right)$} & \multicolumn{2}{c|}{ Yearly Total $\left(\mathrm{MJ} / \mathrm{m}^{2}\right)$} \\
\cline { 2 - 7 } & MEA & EST & MEA & EST & MEA & EST \\
\hline BC & 15.7 & $\mathbf{1 5 . 7}$ & 26.3 & 25.5 & 4275 & 4281 \\
\hline CD & 15.7 & 15.7 & 26.3 & 25.5 & 4275 & 4275 \\
\hline DB & 15.7 & 15.7 & 26.3 & 26.8 & 4275 & 4298 \\
\hline DCBB & 15.7 & 15.7 & 26.3 & 26.0 & 4275 & 4274 \\
\hline
\end{tabular}

The calibrated values of the parameter from 2006 are used to estimate the global radiation of 2008 data. Firstly, all four models are tested by auto optimize result and the estimated values are highly deviate with measured value. Similarly the parameter fitting method is used to estimate the GSR then it is found 
that the estimated value of GSR is very close to the measured value of global solar radiation. The PF based testing values is given in Table 2 .

Table 2: Measured and Model estimated Average Value, Maximum Value and Yearly total Value of Global solar Radiation of Simara 2008

\begin{tabular}{|c|c|c|c|c|c|c|}
\hline \multirow{2}{*}{ Models } & \multicolumn{2}{|c|}{ Average value $\left(\mathrm{MJ} / \mathrm{m}^{2}\right)$} & \multicolumn{2}{|c|}{ Maximum Value $\left(\mathrm{MJ} / \mathrm{m}^{2}\right)$} & \multicolumn{2}{|c|}{ Yearly Total $\left(\mathrm{MJ} / \mathrm{m}^{2}\right)$} \\
\cline { 2 - 7 } & MEA & EST & MEA & EST & MEA & EST \\
\hline BC & 15.3 & 14.9 & 25.5 & 24.4 & 5569 & 5425 \\
\hline CD & 15.3 & 14.8 & 25.5 & 25.8 & 5569 & 5402 \\
\hline DB & 15.3 & 14.7 & 25.5 & 28.8 & 5569 & 5357 \\
\hline DCBB & 15.3 & 15.0 & 25.5 & 25.7 & 5569 & 5458 \\
\hline
\end{tabular}

Table 2, data shows that the measured and model estimated average Value, maximum value and yearly total value of global solar Radiation of model DCBB tentatively equal is found in DCBB model in comparison of the other 3 models $\mathrm{BC}, \mathrm{CD}$ and $\mathrm{DB}$ thus the model $\mathrm{DCBB}$ is the best among other three models to estimate the global solar radiation in this low land region of Nepal in 2008.

\section{Error Analysis of Years 2006 and 2008 data}

Table 3 shows the error analysis in between measured and model estimated data the of global solar radiation in 2006. In 2006 the RMSE is lower in BC model than DCBB however most of the values of MBE, and CRM are lower to compare the BC model and the value of $\mathrm{r}^{2}$ is also greater in DCBB than BC model thus it is confirmed that among the four models the DCBB is the best in terms of statistical analysis.

Table 3: Error Analysis of Year 2006

\begin{tabular}{|c|c|c|c|c|}
\hline Models & $\begin{array}{l}\text { RMSE } \\
(\mathrm{MJ} / \mathrm{m} 2)\end{array}$ & $\begin{array}{c}\text { MBE } \\
(\mathrm{MJ} / \mathrm{m} 2\end{array}$ & $\begin{array}{l}\text { CRM } \\
(\text { No Unit })\end{array}$ & $\begin{array}{c}\mathrm{r}^{2} \\
\text { (No unit) }\end{array}$ \\
\hline BC & 5.13 & 4.45 & -0.02 & 0.34 \\
\hline CD & 5.28 & 4.49 & -0.00 & 0.33 \\
\hline DB & 5.39 & 4.59 & -0.01 & 0.30 \\
\hline Modular DCBB & 5.18 & 4.36 & -0.00 & 0.36 \\
\hline
\end{tabular}

Table 4 shows the error analysis in between model estimated and measured value of global solar radiation of 2008. It is found that the value of RMSE, MBE and CRM is comparatively lower values in DCBB than BC, CD and DB models and the value of $r^{2}$ is higher in DCBB than other three remaining models. It concluded that DCBB model proved the best fit among the other three models.

Table 4: Error Analysis of Year 2008

\begin{tabular}{|c|c|c|c|c|}
\hline Models & $\begin{array}{c}\text { RMSE } \\
(\mathrm{MJ} / \mathrm{m} 2)\end{array}$ & $\begin{array}{c}\text { MBE } \\
\text { MJ/m2) }\end{array}$ & $\begin{array}{c}\text { CRM } \\
\text { (No unit) }\end{array}$ & $\begin{array}{c}\mathrm{r}^{2} \\
\text { (No unit) }\end{array}$ \\
\hline BC & 4.53 & 3.56 & 0.03 & 0.31 \\
\hline CD & 4.64 & 3.59 & 0.03 & 0.32 \\
\hline DB & 5.08 & 3.72 & 0.04 & 0.28 \\
\hline Modular DCBB & 4.39 & 3.37 & 0.02 & 0.39 \\
\hline
\end{tabular}



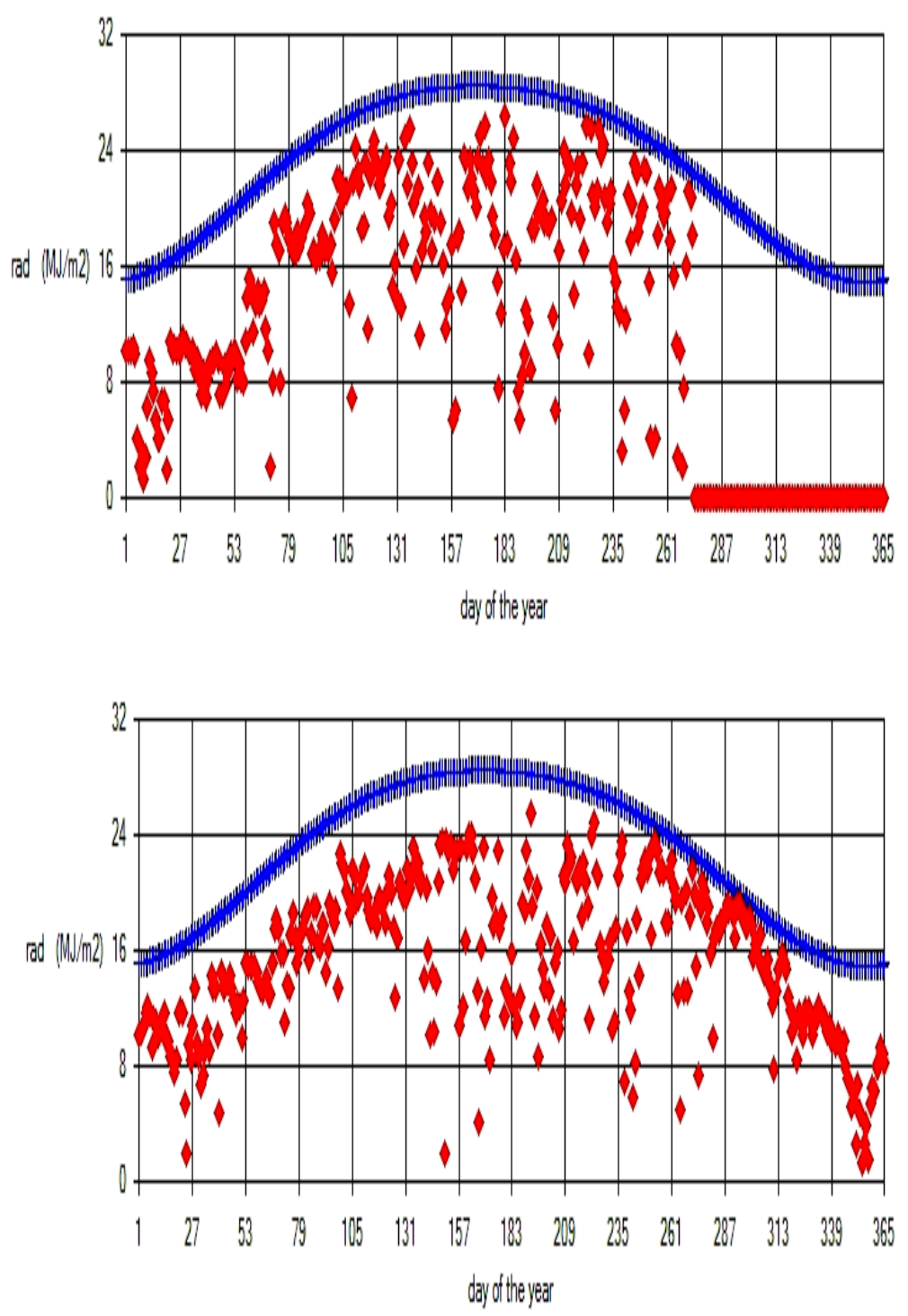

Figures 1 (top) and 2 (bottom): The variation of daily global solar radiation in 2006 and 2008

The figures 1 and 2 show that the variation of global solar radiation with day of the year. The radiation varies significantly due to high concentration of moisture and local weather condition. The average measured values of GSR are about $15.66 \mathrm{MJ} / \mathrm{m}^{2} /$ day and $15.26 \mathrm{MJ} / \mathrm{m}^{2} /$ day in 2006 at and 2008 respectively at Simara. Similarly there is lacking of measured data of solar radiation in 2006 after 273 day number. Thus there is more error is found in RMSE and MBE values in 2006 than in 2008 data of RMSE and MBE. It is clearly shown in table 3 and 4.

Figure 3 and 4 show that coefficient of determination in between estimated value and measured value of solar radiation of 4 models , the DCBB Model is the best because .most of the data are very close to the correlation line with higher value of $\mathrm{r}^{2}$ in 2008 data of Simara. 

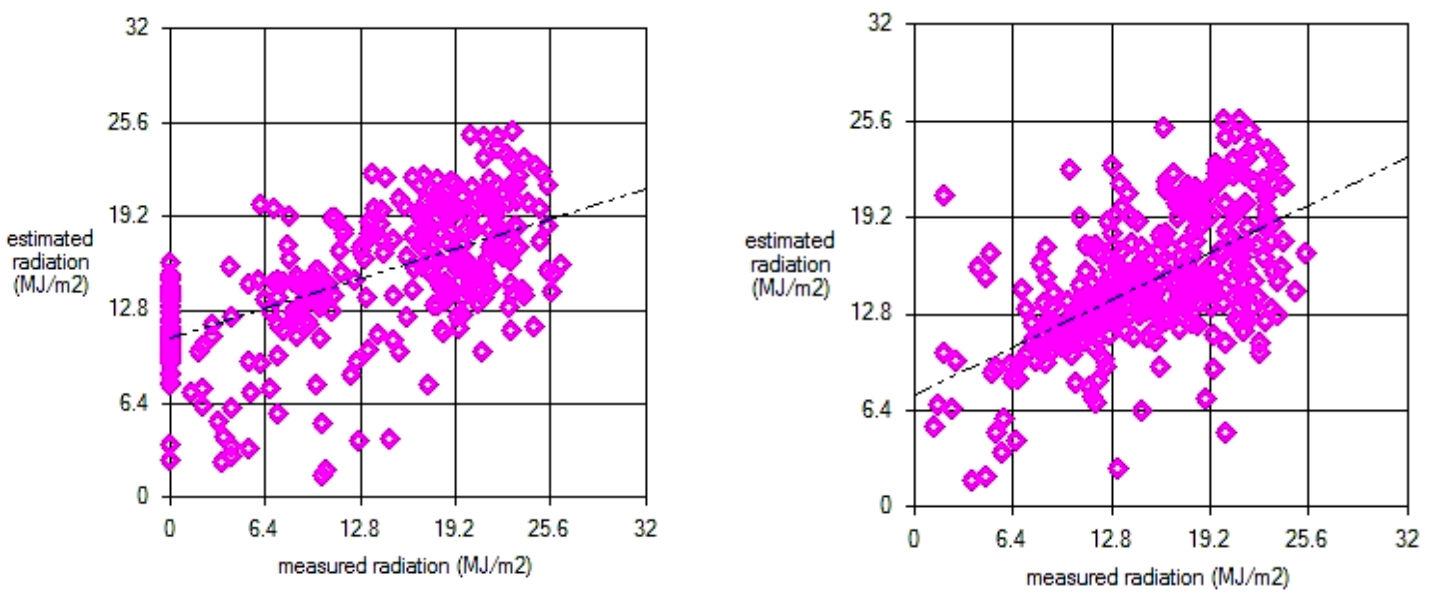

Figure 3(left) and 4 (right): The coefficient of determination in between estimated value and measured value of solar radiation in 2006 and 2008 of DCBB model

Figures 3 and 4 show that there is 0.36 and 0.39 coefficient of determination is found in 2006 and 2008. These values are the maximum in DCBB model in comparison with other three BC, CD and DB models.
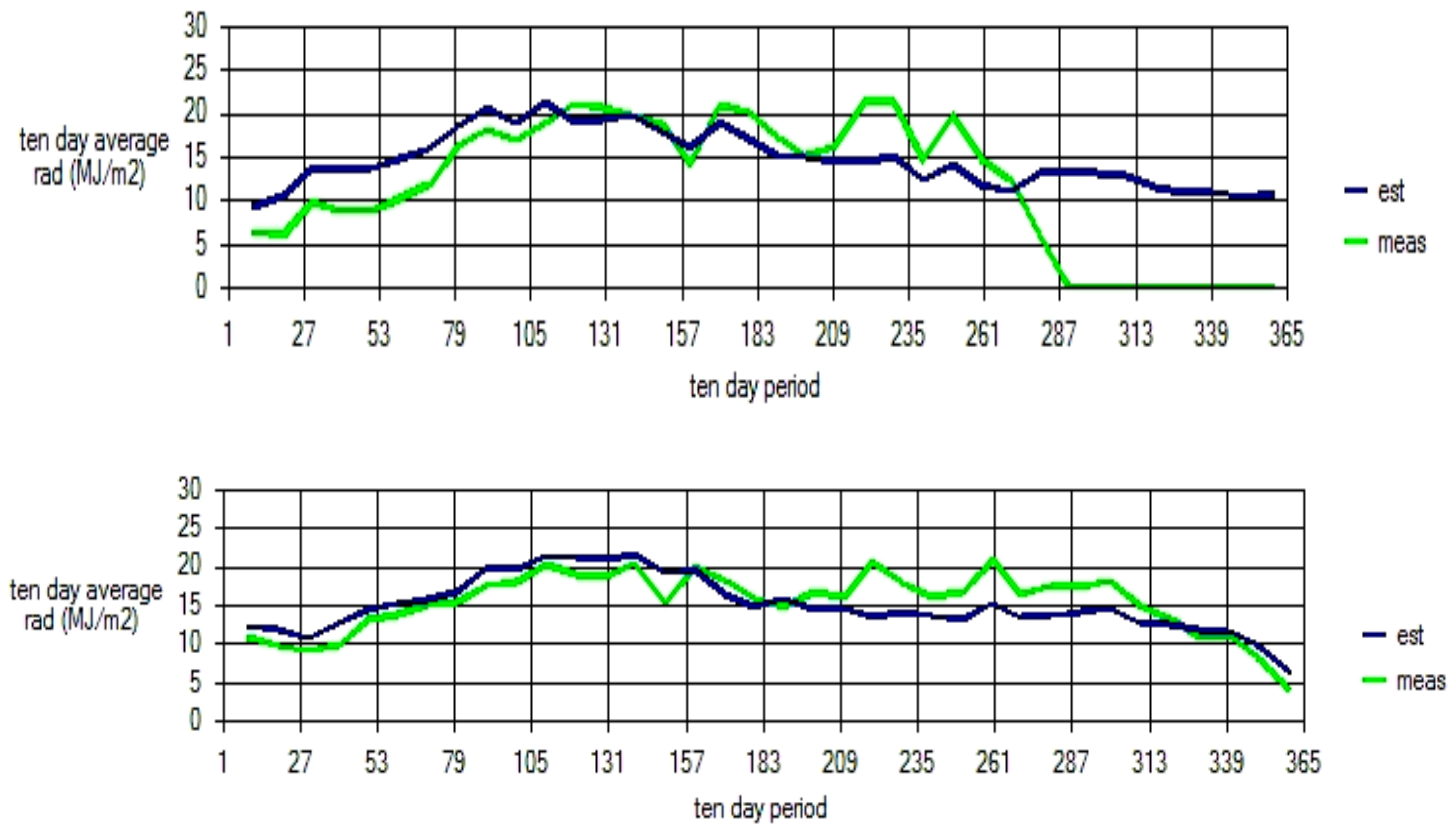

Figures 5 (top) and Figure 6 (bottom): The comparative study of ten days average value of estimated and measured radiation with ten day period in 2006 (top) and in 2008 (bottom). 
Figure 5 shows that there is mostly leading the estimated values of global solar radiation to the measured values of radiation up to the 209 day number in 2006 . However there is missing the measured data after the 273 days. From the 209 day number the measured values of radiation leads to the estimated data because of local weather condition.

Figure 6 shows that there is tentatively the estimated values of radiation leads the measured data up to the 183 day number after that the measured data dominates the estimated value of solar radiation . It is happened due to the local weather condition such as humidity, clouds, wind direction etc.

Table 5 shows the comparative study of finding calibrated model coefficients of Simara Nepal. These data can be utilized to the similar meteorological locations of Nepal.

Table 5: Calibrated Model coefficients for different locations of the World ${ }^{21}$

\begin{tabular}{|c|c|c|c|c|c|c|c|c|c|}
\hline $\begin{array}{l}\mathbf{S} \\
\mathbf{N}\end{array}$ & Models & Parameters & $\begin{array}{l}\text { Cortez } \\
\text { Colorado } \\
\text { (USA) }\end{array}$ & $\begin{array}{l}\text { Padova } \\
\text { (Italy) }\end{array}$ & $\begin{array}{l}\text { Rothams } \\
\text { ted } \\
\text { (UK) }\end{array}$ & $\begin{array}{l}\text { Wageningen } \\
\text { (Netherlands) }\end{array}$ & $\begin{array}{l}\text { Pretoria } \\
\text { (South } \\
\text { Africa) } \\
\end{array}$ & $\begin{array}{l}\text { Griffith } \\
\text { (Australi } \\
\text { a) }\end{array}$ & $\begin{array}{l}\text { Simara } \\
\text { (Nepal ) }\end{array}$ \\
\hline \multirow[t]{2}{*}{1.} & $\mathrm{BC}$ & $\mathrm{b}$ & 0.17 & 0.141 & 0.110 & 0.100 & 0.126 & 0.123 & 0.103 \\
\hline & & $\mathrm{c}$ & 2 & 2 & 2 & 2 & 2 & 2 & 2 \\
\hline \multirow[t]{2}{*}{2.} & $\mathrm{CD}$ & $\mathrm{b}$ & 0.203 & 0.396 & 0.345 & 0.331 & 0.39 & 0.282 & 0.153 \\
\hline & & $T_{\text {nc }}$ & 104.1 & 42.1 & 106.1 & 64.1 & 84.8 & 100.0 & 19.3 \\
\hline \multirow[t]{3}{*}{3} & DB & $\mathrm{b}$ & 0.112 & 0.131 & 0.106 & 0.099 & 0.134 & 0.119 & 0.095 \\
\hline & & $\mathrm{C}_{1}$ & 0.034 & -0.040 & -0.011 & -0.026 & -0.053 & 0.015 & 0.06 \\
\hline & & $\mathrm{C}_{2}$ & 1.410 & 0.008 & 1.183 & 0.215 & 0.041 & 1.137 & 1.045 \\
\hline \multirow[t]{4}{*}{4.} & DCBB & $\mathrm{b}$ & NA & NA & NA & NA & NA & NA & 0.081 \\
\hline & & $\mathrm{C}_{1}$ & NA & NA & NA & NA & NA & NA & 0.044 \\
\hline & & $\mathrm{C}_{2}$ & NA & NA & NA & NA & NA & NA & 0.915 \\
\hline & & Tnc & NA & NA & NA & NA & NA & NA & 96 \\
\hline
\end{tabular}

Source: G.M. Abraha and M.J. Savage $2008^{21}$

\section{Conclusions}

It is concluded that these four models Bristow-Campbell, Campbell- Donatelli, Donatelli Bellocchi and Modular DCBB used to estimate the global solar radiation varying with key parameters and testing by graphical and statistical tools on 2006 and 2008 at Simara Finally the overall performance of the model was evaluated by statistical tools such as root mean square error (RMSE), mean bias error (MBE), Coefficient of Residual Mass (CRM) and coefficient of determination $\left(r^{2}\right)$ at the it is confirmed that . Modular DCBB is the best model for this location for estimation of global solar radiation at samara and other similar meteorological sites of Nepal. the finding model coefficients can further be used in the design and estimation of performance of solar systems at the similar meteorological sites of Nepal.

\section{Acknowledgments}

Authors are grateful to express their gratitude to Solar Radiation and Aerosol in Himalaya Region (SAHR) project of IOE Pulchowk and, Department of Hydrology and Meteorology (DHM), Government of Nepal for providing all necessary meteorological data. We are thankful to FAO-SDRN Agrometerology Group, Rome, Italy and ISCI-Crop Science, Bologna, Italy for providing free version of RadEst 3.00 software and manual through website. Authors are thankful to Prof. S. Gurung, Central Department of Physics , Tribhuvan University Nepal, Prof. Pasquale Daponte University of Sannio, Italy, Prof.Chikashi Sato, Idaho State University, Idaho,USA, Prof. Peter Stahl, University of Wyoming, USA, Prof. Mohan B Dangi, California State University Fresno, USA, and friends Dr. Boris Niraula, Balkrishna Basnet, M. Gurung, E. Dahal, R. B. Shrestha and A. Sharma, NARC, Khumaltar, Lalitpur Nepal for heartly comments, suggestions and support to prepare the paper and to run the RadEst Model 3.00 software . 


\section{References}

1. Water and Energy Commission Secretariat (WECS), Energy Sector Synopsis Report Nepal, 2010.

2. J.N.Shrestha, T.R,Bajracharya, S.R.Shakya, B.Giri, Renewable Energy in Nepal-Progress at a glance from 1998 to 2003, RETRUD-03, 2003, p.1-10.

3. K.N. Poudyal, P. Daponte, L.De Vito, BK Bhattarai, B. Sapkota, Proc. of XVII IMEKO TC-4 Int. Symposium, Kosice, Slovak Rep., 2010.

4. T.R. McVicar, D.L.B. Jupp, Agric. For. Meteorol., 1999, 96, p.219-238.

5. L.Bechini, , G. Duccob, M. Donatelli,. and Stein, Agric. Eco. Environ. 2000, 81, p.29-42.

6. I.E. Akpabio, S.O. UDO, S.E. Etuk, J. of Physics, 2004, 28, p.205-212.

7. A. Angstrom, Meteorol, Soc, 1924, 50, p.121-126

8. G.P. Podesta, L.Nunez, C.A. Villanueva and M.A. Skansi, Agric, for Meterol, 2004, 123, p.41.

9. M. Rivington, G. Bellocchi, K.B. Matthews, and K. Buchan, Agric. for Meteorol 2005, 132, p228.

10. M. Trnka,, Z..Zalud, J.Eitzinger, and M. Dubrovsky, Agric. For Meteorol. 2005,131, p.54.

11. K.L., Bristow, G.S. Campbell, Agric. Forest Meteorol. 1984, 31, p.159.

12. M.Donatelli, . Marletto, Proceedings of the $3^{\text {rd }}$ Congress of the European Society for Agronomy, Padova, Italy, 1994, p.352.

13. M. Donatelli, and G.S. Bellocchi, Proceedings of the fifth congress of the Europ. Soc. Agron. Nitra, Slovakia, II, 1998, p.133.

14. P.G. Jones, P.K., Thornton,. MarkSim, J. of Agron, 2000,92 ,p.445.

15. C.O. Stockle, R.L. Nelson, M. Donatelli, F. Castellvi, Proceedings of the Second International Symposium Modelling Cropping Systems, Florence, Italy, 2001, p.229.

16. M. Donatelli, and G.S. Bellocchi, Cropping Systems, Italy. 2001, p.213.

17. M. Donatelli, G. Bellocchi, and, G. Fontana, J. of Agron, 2003, 18 p.363.

18. http://www.isci.it/tools

19. http://www.sipeaa.it/tools

20. Mannual, Environdata Environmental Monitoring and Management Weather Master 2000 Queensland, 4370, Australia, 1982

21. M.G. Abraha and M.J. Savage, Agric for Material, 2008, 148, p.401. 